\title{
Desempenho alimentar e sobrevivência de Euschistus heros parasitado por Hexacladia smithii em sementes de soja(1)
}

\author{
Maria Clarice Nunes(2) e Beatriz Spalding Corrêa-Ferreira(3)
}

\begin{abstract}
Resumo - Avaliou-se, em laboratório, a influência do parasitóide Hexacladia smithii Ashmead (Hymenoptera: Encyrtidae) na atividade alimentar e sobrevivência de Euschistus heros (Fabricius) (Hemiptera: Pentatomidae), aos 10, 20,30 e 40 dias após o início do parasitismo. A atividade alimentar foi avaliada pelo número de bainhas constatadas nas sementes de soja, Glycine max (L.) Merrill (Fabaceae), em 48 horas de alimentação. $\mathrm{O}$ teste foi mantido sob condições controladas de temperatura $\left(25 \pm 2^{\circ} \mathrm{C}\right)$, umidade $(65 \pm 10 \%)$ e fotoperíodo (14L:10E). No início do desenvolvimento de $H$. smithii a atividade alimentar dos percevejos não-parasitados e parasitados foi semelhante, obtendo-se, entretanto, duas vezes mais bainhas alimentares depositadas/grão pelos machos e fêmeas, após 30 dias de parasitismo. A sobrevivência dos percevejos parasitados foi menor que a dos percevejos não-parasitados, alcançando $100 \%$ de mortalidade 40 a 50 dias após o início do parasitismo. A redução na sobrevivência dos percevejos parasitados por $H$. smithii e a atividade alimentar, semelhante a dos percevejos não-parasitados durante quase todo o período de desenvolvimento do parasitóide, destacam a contribuição desse parasitismo na redução da população do percevejo-marrom E. heros.
\end{abstract}

Termos para indexação: Glycine max, controle biológico, percevejo-marrom, parasitóide, bainhas alimentares.

\section{Feeding activity and survival of the Euschistus heros parasitized by Hexacladia smithii}

\begin{abstract}
The influence of the parasitoid Hexacladia smithii Ashmead (Hymenoptera: Encyrtidae) on the feeding activity and on survival of the neotropical brown stink bug, Euschistus heros (Fabricius) (Hemiptera: Pentatomidae), was evaluated in laboratory, at 10, 20, 30 and 40 days after parasitism. The feeding activity was evaluated through the number of stylet sheaths deposited on soybean seeds, Glycine $\max (\mathrm{L}$.$) Merrill (Fabaceae), after feeding for 48$ hours. The tests were conducted under controlled conditions of temperature $\left(25 \pm 2{ }^{\circ} \mathrm{C}\right), \mathrm{RH}(65 \pm 10 \%)$ and photoperiod (14L:10D). At the beginning of the development of $H$. smithii the feeding activity of non-parasitized and parasitized bugs was similar; however, the number of stylet sheaths was two times greater in seeds fed upon by parasitized stink bugs than those fed upon by non-parasitized bugs, for males and females 30 days after parasitism. The survival of parasitized adults was smaller than that of non-parasitized adults, reaching $100 \%$ of the bugs died after 40 and 50 days of parasitism. The reduction in the survival of the stink bugs parasitized by $H$. smithii and the similar feeding activity among parasitized and nonparasitized bugs during almost the whole period of development of the parasitoids, put in relief the contribution of that parasitism to the reduction of the population of neotropical brown stink bug E. heros.
\end{abstract}

Index terms: Glycine max, biological control, neotropical brown stink bug, parasitoid, stylet sheath.

\section{Introdução}

Entre os sugadores de sementes de soja [Glycine $\max ($ L.) Merrill] (Fabaceae), o percevejo-marrom

\footnotetext{
(1) Aceito para publicação em 3 de dezembro de 2001.

(2)UFPR/Embrapa-Centro Nacional de Pesquisa de Soja (CNPSo), Caixa Postal 231, CEP 86001-970 Londrina, PR. E-mail: clarice@cnpso.embrapa.br

${ }^{(3)}$ Embrapa-CNPSo. E-mail: beatriz@cnpso.embrapa.br
}

Euschistus heros (Fabricius) (Hemiptera: Pentatomidae) é atualmente o percevejo de maior abundância, e é espécie predominante desde o Norte do Paraná até a Região Central do Brasil (CorrêaFerreira \& Panizzi, 1999).

Percevejos causam danos à soja com a introdução do aparelho bucal nas vagens. Ao atingirem as sementes, danificam diretamente os tecidos, tornando-as chochas e enrugadas, afetando, conseqüen- 
temente, a produção e a qualidade dos grãos (Panizzi $\&$ Slansky Junior, 1985). A punctura facilita a contaminação dos grãos por patógenos, e pode ainda causar distúrbios fisiológicos, como a retenção foliar (Todd \& Herzog, 1980).

Segundo Todd \& Herzog (1980), os pentatomídeos fitófagos ao se alimentarem das sementes injetam saliva contendo enzimas digestivas, e sugam o conteúdo liquefeito. $\mathrm{O}$ excesso de saliva ao redor do estilete solidifica-se formando uma bainha na superfície da vagem (Miles, 1972). Essas bainhas têm sido utilizadas como indicadores da atividade alimentar de percevejos pentatomídeos (Bowling, 1980; Panizzi et al., 1995).

Na safra 1996/97, o parasitóide Hexacladia smithii Ashmead (Hymenoptera: Encyrtidae) foi relatado atacando E. heros, em Londrina, PR, apresentando elevada ocorrência natural nos meses de dezembro e janeiro (Corrêa-Ferreira et al., 1998). Os adultos medem de 1,5 a 2,0 mm de comprimento e apresentam coloração preta, os machos apresentam antenas pectinadas, e as fêmeas, antenas filiformes. Esse parasitóide desenvolve-se no interior do percevejo até a fase adulta ( 2 a 39 por hospedeiro), quando emergem por um orifício feito no abdome, após 35 dias de parasitismo (Corrêa-Ferreira et al., 1998; Corrêa-Ferreira \& Panizzi, 1999).

Na concepção do manejo integrado de pragas da soja, o conhecimento de espécies que reduzem naturalmente as populações de pragas é uma necessidade.

Este trabalho teve por objetivo avaliar o efeito do parasitóide $H$. smithii sobre a capacidade alimentar e mortalidade de E. heros.

\section{Material e Métodos}

O trabalho foi realizado em laboratório, na EmbrapaCentro Nacional de Pesquisa de Soja, Londrina, PR, onde se comparou a sobrevivência e a atividade alimentar de E. heros parasitados por $H$. smithii em relação a percevejos não-parasitados. A atividade alimentar foi expressa pelo número de bainhas alimentares ou flanges depositadas na superfície dos grãos de soja pelos percevejos.

Machos e fêmeas de E. heros com dois dias de vida adulta, provenientes de criação em laboratório, foram individualizados em placas de Petri de plástico $(9,0 \times 1,5 \mathrm{~cm})$ e mantidos em estufas incubadoras tipo BOD, em condições controladas de temperatura $\left(25 \pm 2^{\circ} \mathrm{C}\right)$, umidade $(65 \pm 10 \%)$ e fotoperíodo (14L:10E). Durante o teste, no período em que a atividade alimentar não estava sendo avaliada, os percevejos foram alimentados com água e vagens verdes de soja, substituídas sempre que necessário.

Para testar a atividade alimentar, foi oferecido aos machos (50) e fêmeas (50) individualizados, um grão de soja (cultivar BR 37), no estádio de enchimento do grão (R6), segundo escala de Fehr et al. (1971), por 48 horas. Após esse período de alimentação, cada grão foi retirado e submetido ao teste de coloração com fucsina ácida a $1 \%$, por 15 minutos. Em seguida, os grãos foram lavados em água e feita a contagem das bainhas alimentares com auxílio de microscópio estereoscópico (aumento de 10 a 15 vezes).

Após a primeira alimentação em grãos de soja, o total de percevejos foi dividido em dois grupos: percevejos nãoparasitados e percevejos parasitados, sendo estes expostos ao parasitismo por duas fêmeas de $\mathrm{H}$. smithii durante 48 horas, em placas de Petri. Após 10, 20, 30 e 40 dias de parasitismo, percevejos não-parasitados e parasitados foram submetidos a nova avaliação da atividade alimentar, por 48 horas, pelo oferecimento de um grão de soja como alimento, seguindo-se a contagem das bainhas alimentares.

Durante 60 dias, fez-se o acompanhamento diário das placas, observando-se a mortalidade dos percevejos e a emergência dos parasitóides. No grupo de percevejos parasitados, todos foram dissecados ao morrer, sendo considerados aptos para o teste somente aqueles cujo parasitismo foi confirmado pela emergência dos parasitóides adultos ou pela presença de larvas ou pupas no interior do hospedeiro.

Para o teste, utilizou-se delineamento inteiramente casualizado, com dois tratamentos (percevejos nãoparasitados e parasitados), em 25 repetições por sexo, avaliados aos zero, 10, 20, 30 e 40 dias de parasitismo. Os resultados foram submetidos à análise de variância e as médias comparadas pelo teste Tukey, a 5\% de probabilidade. Na análise dos dados de atividade alimentar utilizouse transformação logarítmica $[\log (\mathrm{x}+1)]$.

\section{Resultados e Discussão}

Entre os percevejos que se alimentaram, os parasitados apresentaram maior número de bainhas alimentares que os não-parasitados, durante o desenvolvimento de $H$. smithii. A diferença alimentar foi significativa em relação aos machos, somente nos parasitados por 30 dias, quando os percevejos nãoparasitados apresentaram, em média, seis bainhas por grão e os parasitados um número de bainhas 2,57 vezes maior (Figura 1). Quanto às fêmeas, foi constatada diferença significativa entre os tratamen- 
tos nos percevejos parasitados por 20 e 30 dias, que apresentaram um número de bainhas 2,38 e 2,27 vezes maior que as fêmeas não-parasitadas (Figura 1). Nas avaliações realizadas aos 10 dias, nas fêmeas, e aos 10 e 20 dias, nos machos, não se constatou diferença significativa na atividade alimentar entre percevejos não-parasitados e parasitados.

Entre os percevejos não-parasitados houve um decréscimo no número de indivíduos que se alimentaram com o aumento da idade, chegando a índices de $85,71 \%$ (machos) e $66,67 \%$ (fêmeas) aos 40 dias. Entretanto, entre percevejos parasitados $100 \%$ apresentaram atividade alimentar com até 30 dias de parasitismo. Essa freqüência alimentar dos percevejos parasitados pode ser explicada pelo grande número de larvas do parasitóide em desenvolvimento no seu interior, demandando, portanto, maior atividade alimentar. Entretanto, esta maior atividade alimentar pode ser devida a um maior comportamento de prova sem necessariamente causar maior dano, pois, segundo Nunes (2000), plantas de soja infestadas por 15 dias com percevejos $E$. heros parasitados por $H$. smithii, tendo os parasitóides de 10 a 25 dias de desenvolvimento, apresentaram rendimento e danos semelhantes aos de plantas atacadas por percevejos não-parasitados.

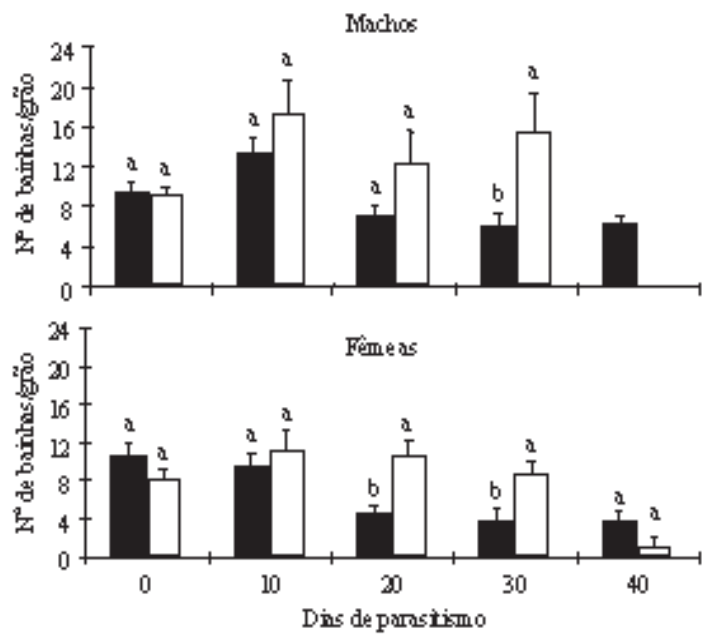

Figura 1. Atividade alimentar (média $\pm E P$ ), em 48 horas de alimentação em grãos de soja, de machos e fêmeas de Euschistus heros não-parasitados ( $\square$ ) e parasitados ( ) por Hexacladia smithii, durante o desenvolvimento do parasitóide. Médias nos tratamentos com mesma letra não diferem entre si pelo teste Tukey, a 5\% de probabilidade.
Após 40 dias de parasitismo, na maioria dos hospedeiros, a emergência dos parasitóides já havia ocorrido, constatando-se acentuada mortalidade. Devido ao reduzido número de machos sobreviventes nessa data, não foi possível a comparação entre os não-parasitados e os parasitados; as fêmeas parasitadas apresentaram reduzida atividade alimentar, com relação às avaliações anteriores (Figura 1).

$\mathrm{Na}$ relação parasitóide-hospedeiro, a literatura revela resultados variáveis, dependendo da planta, do hospedeiro, do parasitóide estudado e do método adotado. Rahman (1970) observou que larvas de Pieris rapae (Linnaeus) (Lepidoptera: Pieridae) tiveram seu consumo aumentado quando parasitadas por Cotesia glomeratus (Linnaeus) (Hymenoptera: Braconidae), enquanto Doetzer \& Foerster (1998) constataram que lagartas de Pseudaletia sequax Franclemont (Lepidoptera: Noctuidae) tiveram consumo menor quando parasitadas por Glyptapanteles muesebecki (Blanchard) (Hymenoptera: Braconidae), embora tenham verificado que o tempo de alimentação do hospedeiro aumentou quando parasitado.

Segundo Salles (1988), plantas de soja infestadas com o Nezara viridula (Linnaeus) (Hemiptera: Pentatomidae) não-parasitados apresentaram quantidade estatisticamente semelhante de sementes picadas $(52,5 \%)$ a plantas infestadas com percevejos parasitados $(30,9 \%)$ por Trichopoda pennipes Fabricius.

Quanto aos E. heros não-parasitados, verificouse diminuição na atividade alimentar com o aumento da idade do percevejo, sendo essa redução mais acentuada a partir dos 20 dias, com valores significativamente inferiores nos machos e fêmeas, aos 30 dias. Nessa data, os machos e as fêmeas apresentaram, em média, 3,52 e 6,85 bainhas a menos que no início da vida adulta, quando apresentaram atividade alimentar de 9,52 bainhas/grão e 10,60 bainhas/grão, respectivamente, em 48 horas de alimentação (Figura 1).

Os percevejos parasitados por $H$. smithii apresentaram flutuação na atividade alimentar, porém não ficou nítida uma relação da alimentação do percevejo em razão do desenvolvimento do parasitóide no interior do hospedeiro. No período de 10 a 40 dias de parasitismo, obtiveram-se valores médios que variaram de 0 a 17,25 bainhas por grão, nos machos, e de 1,00 a 11,07, nas fêmeas (Figura 1). 
Segundo Panizzi (1991), a longevidade de hemípteros sugadores de sementes varia de acordo com o sexo, a atividade sexual e a qualidade nutricional do inseto. A sobrevivência dos E. heros machos não-parasitados e parasitados foi semelhante até 30 dias após o parasitismo (56\%) (Figura 2). Entretanto, percevejos não-parasitados mantiveram essa porcentagem de sobrevivência até 50 dias, enquanto os parasitados foram dizimados aos 40 dias após o início do parasitismo, período em que o parasitóide completou seu desenvolvimento, emergindo e causando a morte do hospedeiro. A sobrevivência de fêmeas parasitadas foi semelhante à de fêmeas não-parasitadas até 20 dias após o início do parasitismo (Figura 2). Aos 50 dias, fêmeas não-parasitadas apresentaram sobrevivência de 36\%, comparado a $0 \%$ de sobrevivência das fêmeas parasitadas. Em média, as fêmeas de E. heros morreram em 3,75 dias após a emergência dos parasitóides adultos, variando de dois a sete dias.

Villas-Bôas \& Panizzi (1980), ao estudarem a biologia de E. heros, observaram que percevejos criados em casa de vegetação apresentavam longevidade média de 119,9 dias (10-265 dias) em machos e 71,8 dias (10-148 dias) em fêmeas. Com o parasitismo por $H$. smithii a longevidade dos percevejos, em média, não ultrapassou 40 dias após o parasitismo. Essa
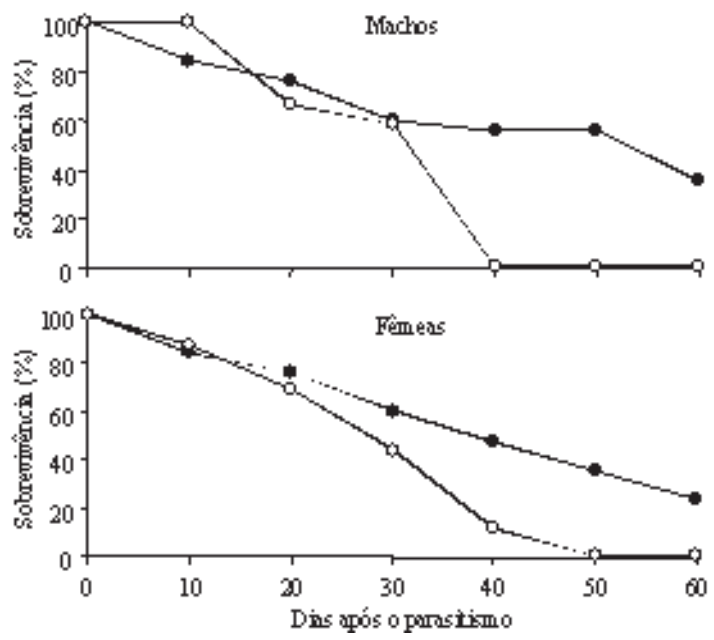

Figura 2. Sobrevivência de machos e fêmeas de Euschistus heros não-parasitados ( ) e parasitados ( ) por Hexacladia smithii, durante o desenvolvimento do parasitóide. redução no tempo de vida do percevejo evidencia o efeito desse parasitóide no controle das populações do percevejo-marrom.

Segundo Salles (1992), um hospedeiro parasitado, para efeito de compensação, pode ter maiores taxas de consumo alimentar em termos relativos, mas dificilmente pode tê-las em termos absolutos, haja vista que a vida útil do hospedeiro parasitado é diminuída drasticamente. A redução na longevidade dos percevejos e a atividade alimentar semelhantes entre percevejos parasitados e não-parasitados durante quase todo o período de desenvolvimento dos parasitóides observadas neste trabalho destacam a contribuição de $H$. smithii no controle biológico do E. heros.

\section{Conclusões}

1. A atividade alimentar dos percevejos E. heros parasitados por $H$. smithii é semelhante à dos percevejos não-parasitados, com exceção da alimentação aos 30 dias após o parasitismo de machos e fêmeas.

2. O parasitismo por $H$. smithii reduz a longevidade de adultos de E. heros, causando $100 \%$ de mortalidade de 40 a 50 dias após o início do parasitismo.

\section{Agradecimentos}

Ao CNPq e à Embrapa-Centro Nacional de Pesquisa de Soja, pelo suporte financeiro e pela infraestrutura para o desenvolvimento da pesquisa; ao Dr. Luis de Santis, pela identificação do parasitóide; ao Dr. Antonio Ricardo Panizzi e ao Dr. Flávio Moscardi, pela correção do artigo.

\section{Referências}

BOWLING, C. C. The stylet sheath as an indicator of feeding activity by the southern green stink bug on soybeans. Journal of Economic Entomology, Lanham, v. 73, n. 1, p. 1-3, Feb. 1980

CORRÊA-FERREIRA， B. S.; NUNES， M. C.; UGUCCIONI, L. D. Ocorrência de Hexacladia smithii Ashmead em adultos de Euschistus heros (F.) no Brasil. Anais da Sociedade Entomológica do Brasil, Londrina, v. 27, n. 3, p. 495-498, set. 1998. 
CORRÊA-FERREIRA, B. S.; PANIZZI, A. R. Percevejos da soja e seu manejo. Londrina: Embrapa-CNPSo, 1999. 45 p. (Circular Técnica, 24).

DOETZER, A. K.; FOERSTER, L. A. Efeito do parasitismo por Glyptapanteles muesebecki (Blanchard) no consumo e utilização do alimento por Pseudaletia sequax Franclemont. Anais da Sociedade Entomológica do Brasil, Londrina, v. 27, n. 2, p. 255-264, jun. 1998.

FEHR, W. R.; CAVINESS, C. E.; BURMOOD, D. T.; PENNINGTON, J. S. Stage of development descriptions for soybeans, Glycine max (L.) Merrill. Crop Science, Madison, v. 11, n. 6, p. 929-931, Nov./Dec. 1971.

MILES, P. W. The saliva of Hemiptera. Advances in Insect Physiology, Cambridge, Inglaterra, v. 9, p. 183-255, 1972.

NUNES, M. C. Efeito do parasitismo de Hexacladia smithii Ashmead (Hymenoptera: Encyrtidae) na capacidade reprodutiva e no dano de Euschistus heros (Fabricius) (Hemiptera: Pentatomidae) causado à soja. 2000. 79 f. Dissertação (Mestrado) - Universidade Federal do Paraná, Curitiba.

PANIZZI, A. R. Ecologia nutricional de insetos sugadores de sementes. In: PANIZZI, A. R.; PARRA, J. R. P. (Ed.). Ecologia nutricional de insetos e suas implicações no manejo de pragas. São Paulo: Manole, 1991. p. 253-287.

PANIZZI, A. R.; NIVA, C. C.; HIROSE, E. Feeding preference by stink bugs (Heteroptera: Pentatomidae) for seeds within soybean pods. Journal of Entomological Science, Tifton, v. 30, n. 3, p. 333-341, July 1995.

PANIZZI, A. R.; SLANSKY JUNIOR, F. Review of phytophagous pentatomids (Hemiptera: Pentatomidae) associated with soybean in the Americas. Florida Entomologist, Gainesville, v. 68, n. 1, p. 184-214, Mar. 1985.

RAHMAN, M. Effect of parasitism on food consumption of Pieris rapae larvae. Journal of Economic Entomology, Lanham, v. 63, n. 3, p. 820-821, June 1970.

SALleS, L. A. B. Parasitism of Nezara viridula (Heteroptera: Pentatomidae) in soybean and other host plant communities. 1988. 191 p. Dissertation (Ph.D.) University of Florida, Florida.

SALLES, L. A. B. Relação entre o tamanho do hospedeiro e do parasitóide desenvolvido, análise do caso: Nezara viridula (Linnaeus 1758) (Hemiptera: Pentatomidae) e Trichopoda pennipes Fabricius, 1794 (Diptera: Tachinidae). Anais da Sociedade Entomológica do Brasil, Porto Alegre, v. 21, n. 1, p. 175-185, 1992.

TODD, J. W.; HERZOG, D. C. Sampling phytophagous pentatomidae on soybean. In: KOGAN, M.; HERZOG, D. C. (Ed.). Sampling methods in soybean entomology. New York: Springer, 1980. p. 438-478.

VILLAS-BÔAS, G. L.; PANIZZI, A. R. Biologia de Euschistus heros (Fabricius, 1798) em soja (Glycine max (L.) Merrill). Anais da Sociedade Entomológica do Brasil, Jaboticabal, v. 9, n. 1, p. 105-113, 1980. 